\title{
A Birandom Chance-Constrained Linear Programming Model for CCHP System Operation Management: A Case Study of Hotel in Shanghai, China
}

\author{
Zhe Bao, ${ }^{1,2}$ Ye Xu ${ }^{D},{ }^{1,2}$ Wei Li, ${ }^{1,2}$ Xu Wang, ${ }^{1}$ Meng R. Li, ${ }^{1,2}$ Ji H. Li, ${ }^{1}$ and Han S. Yang ${ }^{1}$ \\ ${ }^{1}$ MOE Key Laboratory of Regional Energy and Environmental Systems Optimization, \\ College of Environmental Science and Engineering, North China Electric Power University, Beijing 102206, China \\ ${ }^{2}$ Beijing Key Laboratory of Demand Side Multi-Energy Carriers Optimization and Interaction Technique, Beijing 100192, China
}

Correspondence should be addressed to Ye Xu; xuye@ncepu.edu.cn

Received 12 August 2020; Revised 2 October 2020; Accepted 30 October 2020; Published 19 November 2020

Academic Editor: Xander Wang

Copyright $(92020$ Zhe Bao et al. This is an open access article distributed under the Creative Commons Attribution License, which permits unrestricted use, distribution, and reproduction in any medium, provided the original work is properly cited.

Due to its capability to reduce fuel consumption and increase energy efficiency, the combined cooling, heating, and power (CCHP) system has obtained great concern during the last decade. A large number of deterministic and stochastic optimization models were proposed for supporting the operation management of the CCHP system, but few studies noticed that users' demands in the real world may be subjected to twofold randomness with incomplete or uncertain information. In this study, a birandom chance-constrained linear programming (BCCLP) model is developed for identifying optimal operation strategies under random uncertainties. Compared with traditional stochastic programming models, the BCCLP model made the improvement through describing the energy demands as the birandom variables firstly, instead of traditional random variables. This way effectively avoided potential imbalance between energy supply and demand caused by oversimplified expression of uncertain parameters. A gas-fired CCHP system of a hotel in Shanghai, China, was used as a study case for demonstration. A variety of operation strategies are obtained under specific constraints-satisfaction conditions. It is concluded that the BCCLP model was capable of generating the cost-effective operation strategies and evaluating the tradeoffs between system economy and reliability. The influence imposed by some critical parameters on the system performance was examined through the sensitivity analysis, which provided the important guidance to the design and operational management of other similar CCHP systems in the future.

\section{Introduction}

Nowadays, with the rapid improvement of socioeconomic development, industrialization, and urbanization, the electricity and energy requirements were increased at a fast rate in China. The State Grid Energy Research Institute projected the increases in electricity and energy demands from 148 billion MWh and 126 billion MJ in 2018 to 226 billion MWh and 151 billion $\mathrm{MJ}$ in 2035 (growth at two rates of $52.7 \%$ and $19.8 \%$ approximately, resp.). As the main energy form for power generation, the utilization of fossil fuels was accompanied by a large number of pollutants (i.e., nitric oxides, carbon dioxide, and sulfur oxides), which led to global warming and brought serious pressure on ecosystem protection and human health $[1,2]$. According to the 2016
BP Statistical Review of World Energy, China's energy structure has changed in recent years [3]. The proportion of coal consumption has slightly decreased from $69.8 \%$ (in 2012) to $61.47 \%$ (in 2016), while the proportion of nonfossil energy consumption, such as natural gas, has increased from $14.5 \%$ to $19.7 \%$. From the above, it is foreseeable that, in order to reduce coal consumption and promote nonfossil energy development, a low-carbon diversified energy structure would be formed in the future, where the natural gas would play an important role.

Traditional energy-supply modes provided most of the electricity, heat, and cool quantity in large centralized facilities. However, the long-distance transmission network of these plants would cause electrical and thermal loss; meanwhile, the existence of direct discharged and unutilized 
waste heat would reduce the energy-utilization efficiency [4]. With these premises, the distributed energy-supply modes with the cascade utilization of clean energy were favorable to realize the environment protection and sustainable development. Currently, the gas-fired CCHP (combined cooling, heating, and power) puts into use in electricity and energy supply extensively, particularly on a small-scale basis. Gasfired CCHP system has the immense benefits; for example, (i) the operational pattern based on cascade utilization of clean energy has the ability to meet the electricity demand by the aid of GT (gas turbines) or ICE (internal-combustion engines) and simultaneously provide the cold and heat energy through recovering waste heat, while maintaining the high efficiency, keeping the high stability, and producing the minimal greenhouse gas and air pollutant emissions; (ii) as a typical distributed energy system, the properties including short-distance transmission, small physical size, and smallcapacity modules were useful in reducing the electricity and energy loss in the transmission system, without the limitations in the government regulation, utility territory, and land availability; (iii) it had strong adaptability for various buildings, such as baseload generation, emergency backup, and peak/load shaving for industrial parks, university towns, airports, residential buildings, commercial buildings, and office buildings. Generally, a gas-fired CCHP system has strong advantages in protecting the atmospheric environment, improving energy efficiency, and realizing the cost savings. Therefore, its development prospect was expected $[5,6]$.

In recent years, the gas-fired CCHP system has obtained great concern in China [7]. In 2011, the National Development and Reform Commission, Ministry of Finance of the People's Republic of China, Ministry of Housing and UrbanRural Development of the People's Republic of China and National Energy Administration issued the policy "guidance for NG distributed energy resources development" for promoting the utilization of natural gas resources and reducing the fuel consumption. Up to now, as a promising way, the practices of CCHP system for electricity and energy supply are presently spreading quickly in China, especially in the major cities such as Beijing, Shanghai, Tianjin, and Guangzhou, with a highly developed economy and strong dependence on the energy resources. For example, Shanghai Pudong International Airport had a projected CCHP system to generate combined cooling, heating, and electricity for meeting the airport's requirements. Beijing Olympics Energy Exhibition Center gas-fired CCHP system was established to provide all the air-conditioning, heating, domestic hot water, and part of power supply for the large-scale building, including National Stadium, National Aquatics Center, and the Information Building. As so far, the installed capacity of CCHP system has reached 50 million $\mathrm{kW}$ in China.

The practical applications demonstrated that the performances of CCHP systems were strongly influenced by the operational strategy. It is thus necessary to determine the optimal operational strategy of CCHP system for ensuring the high system efficiency and low pollutant emission. In general, there were usually two basic operation strategies for
CCHP systems: following the electric load (FEL) and following the thermal load (FTL), respectively. Some researchers have investigated the operation of CCHP systems under these two operation strategies [8-11]. For example, Mago et al. selected the CCHP and combined heat and power (CHP) systems as the studied targets and analyzed the economic and environmental benefits under various conditions following different operation strategies [8]. Results showed that the systems based on FTL performed better than those based on FEL. Mago and Hueffed presented the comprehensive benefits of a turbine-driven CCHP system with three different operation strategies, that is, FEL, FTL, and following seasonal strategy (FSS), respectively [10]. Comparison results demonstrated the advancements of the above three strategies, where average reductions of the system cost, primary energy consumption, and greenhouse gas emissions reached $2.6 \%, 12.1 \%$, and $40.6 \%$, respectively. Wang et al. analyzed the performance of CCHP system under two operational strategies [11]. It is concluded that greenhouse gas emissions and system cost under the FEL strategy were higher than FTL strategy; correspondingly, the advantage of the FTL strategy was reflected in the primary energy consumption index. From the above mentioned, each of the operational strategies has different strengths and weaknesses. FLT has the advantages in the reduction of energy consumption and the increase in energy-supply reliability. For gas-fired CCHP system, the energy-utilization efficiency and energy provision quality will directly affect the system's performance. It is necessary to develop an operational strategy of CCHP system which realized the high efficiency and sufficient reliability of energy supply and ensured that the users' demands were satisfied. Therefore, the gas-fired CCHP system under FTL strategy was expected.

The design and execution of the optimal operational strategy of CCHP systems were capable of realizing the maximization in total system revenues and thus have been the focus of many studies [12-20]. For instance, Abdollahi and Sayyaadi developed a multiobjective optimization model for realizing the energy-saving, economic, and environmental benefits of small-scale CCHP system [12]. Li et al. formulated an optimization model of the CCHP system aiming to improve the energy-utilization efficiency and economic benefit [14]. Yang and Zhai proposed the numerical model to generate optimal operation strategy of integration of CCHP system and solar thermal utilization [19]. As mentioned above, traditional deterministic optimization models have provided strong technical support for the system configuration and strategy generation, which were helpful in reducing the primary energy consumption, energy cost, emissions, and realizing the improvement in the system performance. However, some limitations in their extensive applications were unavoidable due to the existence of intrinsic and human-induced uncertainties (including the volatility in electric and thermal loads, the fluctuations in the price of electricity, and natural gas as well as the performance of the system equipment) in the CCHP system. Specifically, the electric and thermal loads are mostly presented as the random nature due to the disturbance of external meteorological factors and the deviation caused by 
human' subjective judgments and understandings. The price of electricity and natural gas was influenced by the resources' availability and policy regulations and suitable to describe as the interval values, instead of fixed values. The performance of the system equipment mainly depended on their service time and the operational manner of staff and exhibited uncertain characteristics. Such uncertainties would bring significant difficulties to the formulation of CCHP management models and generation of effective operational strategies. It is thus desired that effective uncertain optimization models be advanced.

Currently, a number of inexact optimization methods have been widely applied in the energy system [21-31]. For instance, Ersoz and Colak developed four stochastic simulation methods for evaluating the investment feasibility of the CCHP system, including the parametric method, the Monte-Carlo method, the historical trend method, and the scenario-based method [22]. Ji et al. proposed a stochastic robust optimization method in CCHP system under random uncertainties [24]. Marino et al. proposed a two-stage stochastic collaborative decision model for supporting energy exchange for a CCHP system [25]. From the above, it can be seen that most researchers focused on dealing with the randomness in electric and thermal demands. That is because, compared with other uncertain variables, it will have a significant influence on energy provision pattern, which are the prominent goals of CCHP system. However, the above discussions about electric and thermal energy demands are mainly regarded as the random variables with a known distribution type as well as fixed distribution parameters. Few studies noticed that electric and thermal energy demands in the real world may be subjected to twofold randomness. In detail, it is widely accepted that electric and thermal energy demands are normally distributed random variable $N\left(\mu, \sigma^{2}\right)$ from the viewpoint of probability theory, where $\mu$ and $\sigma$ represent the mean value and standard deviation, respectively. In fact, $\mu$ and $\sigma$ are identified by various respondents with specific background and preference and may exhibit uncertain characteristics. Specifically, it is first assumed that the energy demands $\xi$ are expressed as the random variables with the normal distributions (i.e., $\xi \sim N(\mu$, $\delta^{2}$ ), where $\mu$ and $\delta$ denote the mean value and standard deviation, respectively. Based on various survey and estimation results from $n$ group of respondents, $n$ groups of random variables could be obtained (i.e., $\left(\mu_{1}, \delta_{1}^{2}\right),\left(\mu_{2}, \delta_{2}^{2}\right), \ldots$, $\left(\mu_{n}, \delta_{n}^{2}\right)$, such that the $\mu$ and $\delta$ values are more suitable to be random variables (as based on the collected data above) rather than fixed values as are traditional random variables. Therefore, the term of $\mu$ and $\sigma$ will become new random variables and electric and thermal energy demands will not be considered to be conventional random variables but the so-called birandom variables, a concept first proposed by Peng and Liu [32]. This concept has been integrated with some inexact multiobjective optimization models and successfully applied to the flow shop scheduling problem, the vendors' selection problem, and the hydropower station operation planning problem [33-35]. Therefore, as the first attempt in the related field, this study is to develop a birandom chance-constrained linear programming (BCCLP) model for generating the operational strategies of gas-fired CCHP systems, where the electricity demands and thermal energy demands will be considered as the birandom variables. A gas-fired CCHP system of a five-star hotel in Shanghai Pudong New Area, China, was used as a study case for demonstration.

The rest of this paper is organized as follows: Section 2 provides an overview of the reference hotel and its energy source and the gas-fired CCHP system, including the load characteristics of the hotel and main components and operational framework of CCHP system. In Section 3, the BCCLP model for gas-fired CCHP systems is formulated and solved based on the primitive chance measure method. Section 4 analyzes the solutions generated from BCCLP model and discusses the sensitivity of critical system parameters. Some meaningful conclusions are summarized in Section 5 .

\section{Case Study}

2.1. Load Characteristics of the Targeted Hotel. To demonstrate the advancement of the proposed optimization model in generating cost-effective and reliable operation strategies for the gas-fired CCHP system, a five-star hotel in Shanghai, China, was selected for this study. This hotel with a height of $90 \mathrm{~m}$ and a total area of $8 \times 10^{4} \mathrm{~m}^{2}$ approximately is located in Pudong district, one of the most prosperous areas in Shanghai with a total GDP of 1046 billion dollars in 2018 . Therefore, the average occupancy rate of this hotel is always maintained at almost more than 80 percent all year. To ensure the high service quality and realize the maximization of economic benefits, the energy-supply security is critical for the long-term development of this hotel.

Figure 1 demonstrates the load characteristics of this hotel, where average monthly electric, cooling, and heating loads are shown in Figure 1(a). Obviously, the cooling and heating loads own remarkable variation trends, where the cooling loads from May to October are much larger than those of other months. The heating loads mainly focus on the months of December to February. It is noteworthy that although the monthly mean temperature in January is the lowest, being $1.9^{\circ} \mathrm{C}$, nevertheless, the heating demands in January are limited. That is because Chinese New Year usually happens in January, leading to a reduction in the number of customers. Compared with the cooling and heating loads, the electricity demands are relatively consistent throughout the year. The average hourly electric, cooling, and heating loads for this building in a typical day are reflected in Figure 1(b). It is shown that the variation in average hourly electric loads in both summer and winter is synchronous with the design of local step tariff, which is divided into three periods, as peak period (8:00-11:00 and 18:00-21:00), flat period (6:00-8:00, 11:00-18:00, and 21:0022:00), and valley period (22:00-6:00). Meanwhile, the shifts in outdoor temperature have an obvious influence on the heating and cooling loads. Specifically, the heating loads are very large in winter, being in a range of 4866.01 to $16474.03 \mathrm{~kW}$, while being relatively lower in summer from 49.85 to $1052.53 \mathrm{~kW}$; the cooling loads are higher in summer 


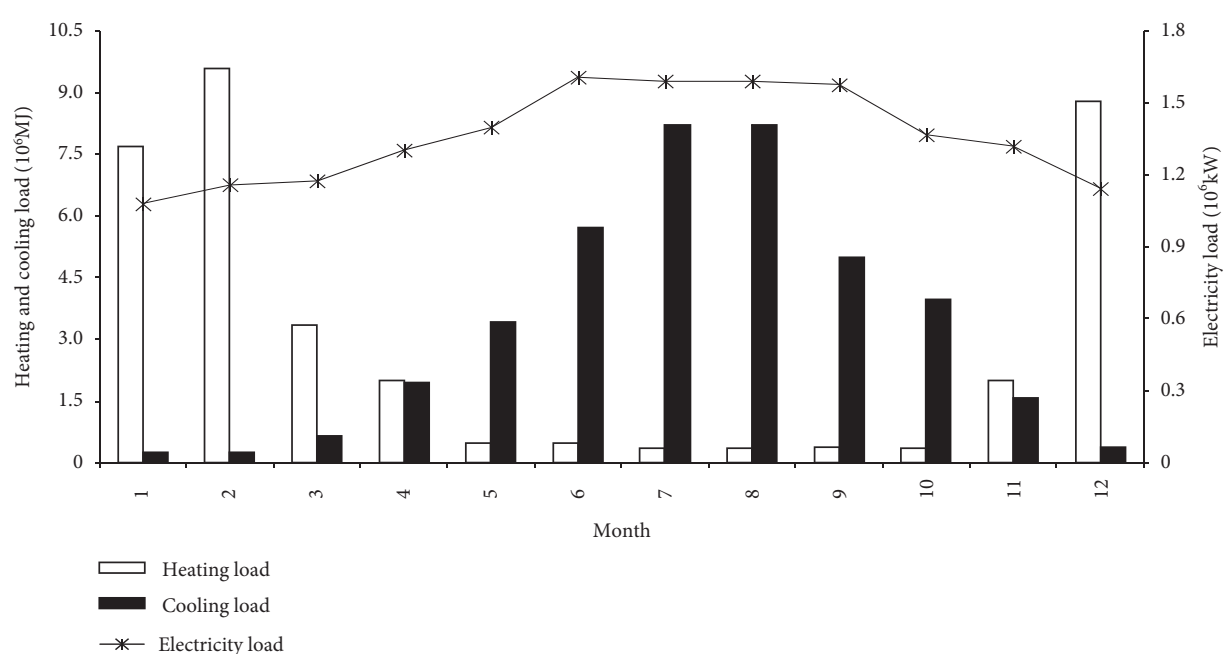

(a)

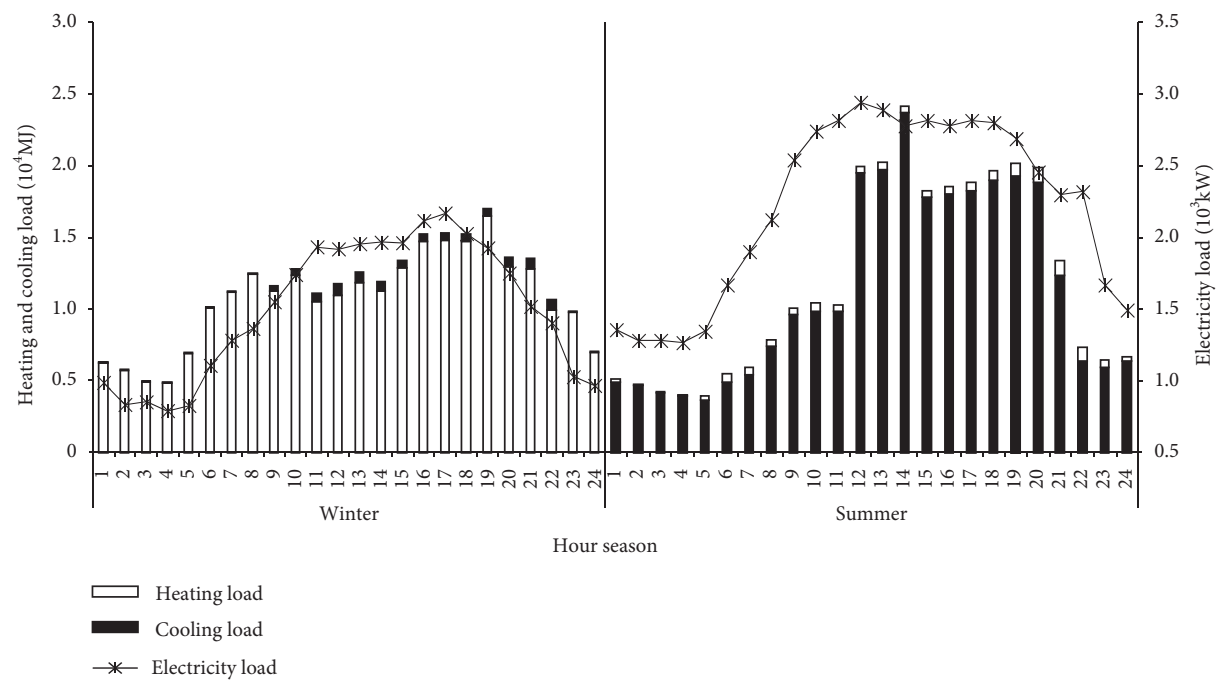

(b)

FIGURE 1: Electrical, cooling, and heating load of the hotel. (a) Average monthly load curves; (b) typical daily load curves over three seasons.

with 3712.71 to $23751.53 \mathrm{~kW}$ than that in winter from 12.94 to $818.71 \mathrm{~kW}$. As mentioned above, the changes in outdoor temperature and electricity price have obvious influences on the heating, cooling, and electric loads, where the loads exhibited obvious variation trends. Therefore, it is essential for the CCHP system to identify accurate energy demands in order to generate a reasonable and feasible schedule strategy. In this study, the energy demands were described as the birandom variables (as depicted in Section 3) for reflecting their dynamic variation characteristics.

\subsection{The Configuration and Operational Mechanism of the} CCHP System. The schematic diagram of the gas-fired CCHP system is shown in Figure 2. The gas-fired CCHP system is composed of many modules, including a gas turbine (GT) with a total rated capacity of $6 \mathrm{MW}$, unfired dual pressure natural circulation heat recovery steam generators (HRSG), auxiliary boiler $(\mathrm{AB})$, absorption chillers $(\mathrm{AC})$, heat exchanger (HE), and electrical chillers (EC).
The operational framework of CCHP system is described as follows: firstly, the gas-fired turbine burns the natural gas and generates the electricity and high-temperature flue gas. Secondly, the high-temperature flue gas, produced as a byproduct and recovered by HRSG, is utilized by the AC or HE for meeting cooling and heating demands. It is regulated that if GT is incapable of supplying enough electricity or byproduct heat, additional electricity and fuel need to be purchased to compensate for meeting users' requirements. Next, it is designed that the insufficient cooling load is satisfied by EC based on the electricity generated by GT in priority or purchased from the grid. As for the unsatisfied heating load, it is provided by the AB through burning the natural gas. Finally, the gas-fired CCHP system is connected to the public supply network. It is regulated that the unsatisfactory electricity loads are purchased from the public power grid; nevertheless, the surplus electricity provided by the CCHP system is unavailable for the public power grid. This is because the transmission of excess electricity to the power grid will lead to the voltage flicker and short-circuit current, which affect the security and reliability of the power grid. 


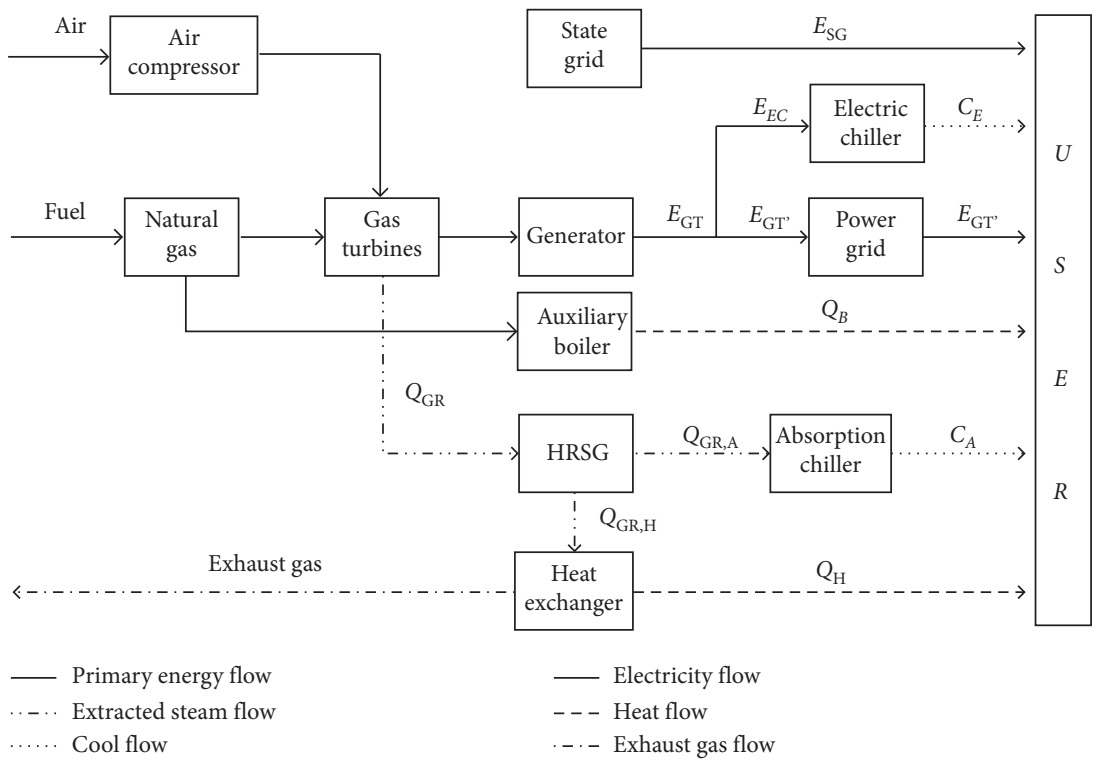

Figure 2: Structure and energy flow of the gas-fired CCHP system.

2.3. The Main Problems Associated with the CCHP System. As demonstrated [36], compared with traditional energysupply pattern, CCHP system is capable of improving the overall efficiency, where less primary fuel is consumed to generate the same amount of electricity and thermal energy. However, there are still some problems which should be solved at this stage. (i) The mode at FTL operation strategy caused the surplus electricity, which accounted for $10 \%$ of the total electricity quantity among a year. It reached the highest value in winter, being $18 \%$. (ii) The intrinsic uncertainties are associated with the gas-fired CCHP system, such as the volatility in electric and thermal loads, the fluctuations in the price of electricity and natural gas, and the unstable nature of equipment performance. The oversimplification in those uncertainties may affect the accuracy and rationality of the designed operational strategy. (iii) The site survey results indicated that the overall efficiency of the CCHP system is approximately $72 \%$, which means that there still would be some improvement spaces in the system efficiency. It is thus expected to formulate an optimization model under random uncertainty, aiming to generate the cost-effective operational strategy of targeted gas-fired CCHP system.

\section{The Operation Optimization Model of the Targeted CCHP System}

3.1. Formulation of the BCCLP Model for the CCHP System. In this research, a BCCLP model was formulated for realizing the minimal system cost, improving the energy-utilization efficiency, and dealing with the uncertainties in the system. The model objective is to minimize operating cost and maintenance cost of the CCHP system; correspondingly, the constraints include the supply balance of electricity, heating, and cooling and operational limitations of system equipment, as well as nonnegative constraints.

Objective function:

$$
\begin{aligned}
& \text { minimize } f=f_{1}+f_{2}, \\
& f_{1}=C_{\mathrm{ng}} \sum_{t=1}^{T} \operatorname{ngt}(t)+\operatorname{ngb}(t)+C_{\text {elec }} \sum_{t=1}^{T} E_{\mathrm{sg}}(t), \\
& f_{2}=C_{\mathrm{GT}} \sum_{t=1}^{T} E_{\mathrm{GT}}(t)+C_{B} \sum_{t=1}^{T} \mathrm{Q}_{B}(t)+C_{\mathrm{AC}} \sum_{t=1}^{T} C_{A}(t) \\
& \quad+C_{\mathrm{EC}} \sum_{t=1}^{T} C_{E}(t),
\end{aligned}
$$

where $f_{1}$ is the total operational cost of the CCHP system in period $t(\mathrm{RMB}) ; f_{2}$ is the total maintenance cost of the CCHP system in period $t(\mathrm{RMB}) ; t$ is the index of time period; $C_{\mathrm{ng}}$ $(t)$ is the natural gas price in period $t\left(\mathrm{RMB} / \mathrm{m}^{3}\right) ; C_{\text {elec }}(t)$ is the electricity price in period $t(\mathrm{RMB} / \mathrm{kWh}) ; \operatorname{ngt}(t)$ is the natural gas consumption of the gas turbine in period $t\left(\mathrm{~m}^{3}\right)$; $\mathrm{ngb}(t)$ is the natural gas consumption of the auxiliary boiler in period $t\left(\mathrm{~m}^{3}\right) ; E_{\mathrm{sg}}(t)$ is the electricity purchased from the power grid in period $t(\mathrm{kWh}) ; C_{\mathrm{GT}}$ is the maintenance cost of the gas turbine $(\mathrm{RMB} / \mathrm{kWh}) ; C_{B}$ is the maintenance cost of the auxiliary boiler $(\mathrm{RMB} / \mathrm{MJ})$; $C_{A C}$ is the maintenance cost of the absorption chiller $(\mathrm{RMB} / \mathrm{MJ}) ; C_{\mathrm{EC}}$ is the maintenance cost of the electricity chiller $(\mathrm{RMB} / \mathrm{MJ}) ; E_{\mathrm{sg}}(t)$ is purchased electricity from local grid in period $t(\mathrm{kWh}) ; E_{\mathrm{GT}}(t)$ is the electricity generated from the gas turbine in period $t(\mathrm{~kW})$; $Q_{B}(t)$ is the quantity of heat sourced from the auxiliary boiler in period $t(\mathrm{MJ}) ; C_{A}(t)$ is the quantity of cool provided by the absorption chiller in period $t(\mathrm{MJ}) ; C_{E}(t)$ is the quantity of cool sourced from the electrical chiller in period $t$ (MJ). As demonstrated in the objective function (1a)-(1c), equation (1b) was established for calculating the total operational costs of the CCHP system, where they are composed of two parts, that is, the purchasing costs of electricity and the combustion costs of natural gas, respectively. Equation (1c) was the function for describing the total 
maintenance costs of the CCHP system, which include the maintenance costs of gas turbine, absorption chillers, electrical chillers, and auxiliary boiler, respectively. The decision variables mainly include ngt $(t)$, ngb $(t), E_{\mathrm{sg}}(t), E_{G T}$ $(t), Q_{B}(t), C_{A}(t)$, and $C_{E}(t)$, respectively.

Subject to the following,

(i) Electricity balance:

$$
\begin{aligned}
E_{\mathrm{SG}}(t)+E_{\mathrm{GT}^{\prime}}(t) & \geq E(t), \\
E_{\mathrm{GT}}(t) & =\operatorname{ngt}(t) H_{\mathrm{ng}} \eta_{\mathrm{pe}} \eta_{\mathrm{te}}, \\
E_{\mathrm{GT}^{\prime}}(t) & =E_{\mathrm{GT}}(t)-E_{\mathrm{EC}}(t), \\
E_{\mathrm{EC}}(t) & =\frac{C_{E}(t)}{\mathrm{COP}_{\mathrm{EC}}},
\end{aligned}
$$

where $E_{\mathrm{GT}^{\prime}}(t)$ is the electricity output sourced from the gas turbine in period $t(\mathrm{kWh}) ; \widetilde{E}(t)$ is the electricity load demand of the building in period $t$ $(\mathrm{kWh}) ; H_{\mathrm{ng}}$ is the low calorific value of natural gas $\left(\mathrm{MJ} / \mathrm{m}^{3}\right) ; \eta_{\mathrm{pe}}$ is the electrical efficiency of the gas turbine; $\eta_{\mathrm{te}}$ is the thermal efficiency of the gas turbine; $E_{\mathrm{EC}}(t)$ is the electricity consumption for the electrical chillers in period $t(\mathrm{kWh}) ; C_{E}(t)$ is the quantity of cool generated from the electrical chillers in period $t(\mathrm{MJ})$; $\mathrm{COP}_{\mathrm{EC}}$ is the COP (coefficient of performance) value of the electrical chillers. Constraint (1d) regulated that the summation of generated and purchased electricity must be greater than or equal to practical demand in period $t$. Constraints (1e)-(1g) described how to calculate the electricity flow of the entire CCHP system in period $t$.

(ii) Heat balance:

$$
\begin{aligned}
Q_{H}(t)+Q_{B}(t) & =H_{Q}(t), \\
Q_{H}(t) & =U_{\mathrm{ST}}(t) \theta(t) \eta_{\mathrm{oeh}}, \\
\mathrm{ST}(t) & =\frac{\operatorname{ET~}(t)\left(1-\eta_{\mathrm{te}}\right)}{\eta_{\mathrm{pe}} \eta_{\mathrm{te}}}, \\
Q_{B}(t) & =\operatorname{ngb}(t) \eta_{\mathrm{ceb}} H_{\mathrm{ng}}, \\
0 & \leq U_{\mathrm{ST}}(t) \leq 1,
\end{aligned}
$$

where $Q_{H}(t)$ is the heat output sourced from the heat exchange in period $t(\mathrm{MJ}) ; Q_{B}(t)$ is the heat output generated by the auxiliary boiler in period $t$ (MJ); $H_{Q}(t)$ is the heating demand of the building in period $t(\mathrm{MJ})$; $U_{\mathrm{ST}}(t)$ is the recovery waste heat of the CCHP system in period $t(\mathrm{MJ}) ; \theta(t)$ is the proportion of the recovery waste heat allocated to the heat exchanger in period $t ; \eta_{\text {oeh }}$ is exhaust heat exchanger efficiency; $\eta_{\text {ceb }}$ is the auxiliary boiler efficiency. Constraint (1f) required that the supplied heating amount must be equal to practical demand in period $t$. Constraints (1g)-(1i) define the heating power from heat exchanger and auxiliary boiler in period $t$, respectively. Constraint (1j) ensured that the value $U_{\mathrm{ST}}(t)$ belongs the $[0,1]$ range.

(iii) Cool balance:

$$
\begin{aligned}
C_{A}(t)+C_{E}(t) & =C(t), \\
C_{A}(t) & =\mathrm{ST}(t)\left(1-U_{\mathrm{ST}}(t)\right) \eta_{\mathrm{hrer}} \mathrm{COP}_{\mathrm{AC}},
\end{aligned}
$$

where $C(t)$ is the cooling demand in period $t(\mathrm{MJ})$; $\eta_{\text {hrer }}$ is the heat efficiency of the absorption chillers; $\mathrm{COP}_{\mathrm{Ac}}$ is the COP (coefficient of performance) of the absorption chillers. Constraint (1k) was the function of the amount of total cooling supply that must be equal to the practical demand. Constraint (11) restricted the cooling power from the absorption chillers in period $t$.

(iv) Other constraints:

$$
\begin{aligned}
& 0 \leq \mathrm{ET}(t) \leq \mathrm{ET}_{\text {Max }}, \\
& 0 \leq Q_{H}(t) \leq Q_{H \text { Max }}, \\
& 0 \leq Q_{B}(t) \leq Q_{B \text { Max }}, \\
& 0 \leq C_{A}(t) \leq C_{A \text { Max }}, \\
& 0 \leq C_{E}(t) \leq C_{E \text { Max }},
\end{aligned}
$$

where $\mathrm{ET}_{\mathrm{Max}}$ is the maximum generation power of the gas turbine $(\mathrm{kW}) ; Q_{H \text { Max }}$ is the maximum generation power of the heat exchanger (MJ); $Q_{B}$ Max is the maximum generation power of the auxiliary boiler $(\mathrm{MJ}) ; C_{A}$ Max is the maximum generation power of the absorption chiller $(\mathrm{MJ}) ; C_{E \operatorname{Max}}$ is the maximum generation power of the electrical chiller (MJ). Constraints $(1 \mathrm{~m})$ to $(1 \mathrm{q})$ denoted that energy generated from relevant facilities must not exceed their generation capacity limits.

In this study, the BCCLP model was solved by the commercial software LINGO 12.0, which is a powerful tool to assist in formulating and solving the optimization models. The previous studies have demonstrated that LINGO is advantageous in tackling the energy and environmental management issues faster and simpler due to its easy-to-edit language and low computational burden $[24,37]$. This is the reason why it was explored to support the operation management of CCHP system in this research. The hardware 
setting for running LINGO in this study is listed as follows: (1) Operation System: Microsoft Windows 10; (2) CPU: Intel (R) Core (TM) i5-cc60U @ 3.20 GHz 3.20 GHz; (3) RAM: $4 \mathrm{~GB}$.

3.2. Data Information. The parameters involved in the BCCLP model are divided into two types, including the parameters associated with the CCHP system and the parameters related to the users, respectively.

3.2.1. CCHP System Parameters. Based on on-site survey, the regulations released by the electricity authority, Shanghai Statistics Bureau, and Shanghai Statistics yearbook, the economic and technical parameters of CCHP system are identified and reflected in Table 1 . The electricity price is divided into three levels, being $0.333 \mathrm{RMB} / \mathrm{kWh}$ at the valley time, $0.653 \mathrm{RMB} / \mathrm{kWh}$ at the flat time, and $1.104 \mathrm{RMB} / \mathrm{kWh}$ at the peak time, respectively. As for the natural gas price, it mainly depended on the market. Moreover, it is found that the maintenance costs and technical parameters of system facilities are stable relatively and thus are assumed to be deterministic values.

3.2.2. Energy-Demand Parameters. According to the on-site survey results, historical data record (from 2010 to 2018), the energy-demand parameters, including the electricity, heating, and cooling demands, are provided in Table 2. In this CCHP system, as described in the "Introduction" section, the energy requirements are affected by many factors, such as the population, production scale, and local meteorological condition, leading to the large variation range. Therefore, they are designed as the birandom variables with normal probability distribution.

3.3. The Solution Algorithm of the Formulated BCCLP Model. Based on the equilibrium chance-constrained measure proposed by (Peng and Liu, 2007), the constraints which included birandom parameters can be transformed to their equivalent deterministic forms as follows:

$$
\begin{aligned}
A(\omega) X & \leq B(\omega) \Longleftrightarrow \operatorname{Ch}^{e}\{A(\omega) X \leq B(\omega)\} \geq 1-\alpha_{r} \\
& \Longleftrightarrow \operatorname{Pr}\left\{\omega \in \Omega \mid \operatorname{Pr}\{A(\omega) X \leq B(\omega)\} \geq 1-\alpha_{r}\right\} \geq 1-\alpha_{r} \\
& \Longleftrightarrow \mu_{A} X-\Phi^{-1}\left(\alpha_{r}\right) \sqrt{(X)^{T} \sigma_{A} X+\left(\sigma_{B}\right)^{2}} \\
& -\Phi^{-1}\left(\alpha_{r}\right) \sqrt{(X)^{T} \sigma_{A^{\prime}} X+\left(\sigma_{B^{\prime}}\right)^{2}} \leq \mu_{B}, \quad \forall r,
\end{aligned}
$$

$$
\begin{aligned}
& \widetilde{\widetilde{D}}(\omega) X \geq \widetilde{\widetilde{E}}(\omega) \\
& \Longleftrightarrow \operatorname{Ch}^{e}\{D(\omega) X \geq E(\omega)\} \geq 1-\alpha_{r} \\
& \Longleftrightarrow \operatorname{Pr}\left\{\omega \in \Omega \mid \operatorname{Pr}\{D(\omega) X \geq E(\omega)\} \geq 1-\alpha_{r}\right\} \\
& \geq 1-\alpha_{r} \\
& \Longleftrightarrow \mu_{D} X+\Phi^{-1}\left(\alpha_{r}\right) \sqrt{(X)^{T} \sigma_{D} X+\left(\sigma_{E}\right)^{2}} \\
&+\Phi^{-1}\left(\alpha_{r}\right) \sqrt{(X)^{T} \sigma_{D^{\prime}} X+\left(\sigma_{E^{\prime}}\right)^{2}} \geq \mu_{E}, \quad \forall r
\end{aligned}
$$

where $\mathrm{Ch}^{e}\{\cdot\}$ denotes the primitive chance of birandom event $\{\cdot\} ; \alpha_{r}$ is a given level for birandom constraint (i.e., the significance level, which represents the admissible risk of constraint violation), which implies that the constraint should be satisfied with at least a probability level of $1-\alpha_{r} . \alpha_{r}$ is a predetermined violation level for the birandom constraint (i.e., the admissible risk of constraint violation), which implies that the constraint should be satisfied with at least a probability level of $1-\alpha_{r}$. The design principle of $\alpha_{r}$ value is that its range is wide as possible. The principle of designing the $\alpha_{r}$ value is ensuring its ranges are wide enough. In order to generate a variety of decision alternatives and provide more choosing opportunities to decision makers, a relatively wide range of designed parameter is necessary. Various $\alpha$ values are helpful for investigating the risks caused by demand-constraint violation, generating desired solutions of electricity and energy supply, and useful for managers in gaining insight into tradeoff between system cost and constraint-violation risk. $\varphi$ is the standard normal distribution. According to inequations (2a) and (2b), model (1) can be converted into the corresponding deterministic model, where constraints (1c), (1i), and (1n) can be transformed as follows:

$$
\begin{gathered}
E_{\mathrm{SG}}(t)+E_{\mathrm{GT}^{\prime}}(t) \geq E(t) \Leftrightarrow \operatorname{Ch}^{e}\left\{E(t) \mid E_{\mathrm{SG}}(t)+E_{\mathrm{GT}^{\prime}}(t) \geq E(t)\right\} \geq 1-\alpha_{r}, \\
Q_{H}(t)+Q_{B}(t) \geq H_{Q}(t) \Leftrightarrow \operatorname{Ch}^{e}\left\{H_{Q}(t) \mid Q_{H}(t)+Q_{B}(t) \geq H_{Q}(t)\right\} \geq 1-\alpha_{r}, \\
C_{A}(t)+C_{E}(t) \geq C(t) \Leftrightarrow \operatorname{Ch}^{e}\left\{C(t) \mid C_{A}(t)+C_{E}(t) \geq C(t)\right\} \geq 1-\alpha_{r} .
\end{gathered}
$$

Finally, the solutions of the BCCLP model were obtained, that is, $f_{\text {opt }}$, ngt $(t)_{\text {opt }}$, ngb $(t)_{\text {opt }}, E_{\mathrm{SG}}(t)_{\text {opt }}, E_{\mathrm{GT}}(t)_{\text {opt }}, Q_{B}(t)_{\text {opt }}, C_{A}$ $(t)_{\mathrm{opt}}$, and $C_{E}(t)_{\mathrm{opt}}$, respectively. The procedures of formulating and solving BCCLP model are summarized as follows:
Step 1. Collect system data and identify uncertain variables as the birandom variables.

Step 2. Determine the objective function and constraints in the proposed BCCLP model. 
TABLe 1: Part of CCHP system parameters.

\begin{tabular}{lc}
\hline Parameters & Value \\
\hline Major economic parameters & $0.03 \mathrm{RMB} / \mathrm{kWh}$ \\
Maintenance cost of gas turbine & $0.0002 \mathrm{RMB} / \mathrm{MJ}$ \\
Maintenance cost of absorption chiller & $0.0006 \mathrm{RMB} / \mathrm{MJ}$ \\
Maintenance cost of auxiliary boiler & $0.0005 \mathrm{RMB} / \mathrm{MJ}$ \\
Maintenance cost of electricity chiller & $1.104 \mathrm{RMB} / \mathrm{kWh}$ \\
Electricity price in peak period & $0.653 \mathrm{RMB} / \mathrm{kWh}$ \\
Electricity price in flat period & $0.333 \mathrm{RMB} / \mathrm{kWh}$ \\
Electricity price in valley period & $2.32 \mathrm{RMB} / \mathrm{m}^{3}$ \\
Natural gas prices & 0.776 \\
\hline Major technical parameters & 0.8 \\
Efficiency of exhaust heat exchanger & 0.18 \\
Electrical efficiency of gas turbine & 0.85 \\
Thermal efficiency of gas turbine & 0.695 \\
Efficiency of auxiliary boiler & $35.175 \mathrm{MJ} / \mathrm{m}^{3}$ \\
Recovery waste heat efficiency of the absorption chillers & 1.2 \\
Low calorific value of natural gas & 4.45 \\
Rated COP of absorption chiller & \\
Rated COP of electric chiller & \\
\hline
\end{tabular}

TABle 2: Part of energy-demand parameters.

\begin{tabular}{lcccc}
\hline \multirow{2}{*}{ Parameter } & Time (hour) & Winter & $\begin{array}{c}\text { Probability distribution } \\
\text { Transition }\end{array}$ & Summer \\
\hline & 0 & $N \sim(\mu, 17.47) \mu \sim(957.59,12.32)$ & $N \sim(\mu, 18.92) \mu \sim(1144.73,13.28)$ & $N \sim(\mu, 21.26) \mu \sim(1483.59,14.84)$ \\
Electricity demand & 5 & $N \sim(\mu, 16.30) \mu \sim(818.24,11.53)$ & $N \sim(\mu, 18.46) \mu \sim(1084.25,12.98)$ & $N \sim(\mu, 20.27) \mu \sim(1335.76,14.18)$ \\
& 10 & $N \sim(\mu, 22.79) \mu \sim(1729.39,15.86)$ & $N \sim(\mu, 25.19) \mu \sim(2151.23,17.46)$ & $N \sim(\mu, 28.12) \mu \sim(2729.59,19.42)$ \\
& 15 & $N \sim(\mu, 24.08) \mu \sim(1950.92,16.72)$ & $N \sim(\mu, 26.06) \mu \sim(2315.38,18.04)$ & $N \sim(\mu, 28.47) \mu \sim(2803.50,19.65)$ \\
& 20 & $N \sim(\mu, 22.86) \mu \sim(1740.10,15.90)$ & $N \sim(\mu, 25.10) \mu \sim(2133.95,17.40)$ & $N \sim(\mu, 26.72) \mu \sim(2444.49,18.48)$ \\
\hline & 0 & $N \sim(\mu, 3.45) \mu \sim(8.36,2.96)$ & $N \sim(\mu, 12.17) \mu \sim(414.07,8.78)$ & $N \sim(\mu, 42.04) \mu \sim(6412.24,28.69)$ \\
Cooling demand & 5 & $N \sim(\mu, 3.45) \mu \sim(8.36,2.96)$ & $N \sim(\mu, 8.85) \mu \sim(187.62,6.57)$ & $N \sim(\mu, 32.41) \mu \sim(3699.37,22.27)$ \\
& 10 & $N \sim(\mu, 12.17) \mu \sim(413.80,8.78)$ & $N \sim(\mu, 29.22) \mu \sim(2963.16,20.14)$ & $N \sim(\mu, 51.73) \mu \sim(9892.39,35.15)$ \\
& 15 & $N \sim(\mu, 13.14) \mu \sim(496.56,9.43)$ & $N \sim(\mu, 34.99) \mu \sim(4354.16,24.00)$ & $N \sim(\mu, 68.68) \mu \sim(17784.38,46.45)$ \\
& 20 & $N \sim(\mu, 14.54) \mu \sim(629.47,10.36)$ & $N \sim(\mu, 34.65) \mu \sim(4263.59,23.77)$ & $N \sim(\mu, 70.70) \mu \sim(18880.49,47.80)$ \\
\hline Heating demand & 0 & $N \sim(\mu, 43.78) \mu \sim(6982.48,29.85)$ & $N \sim(\mu, 27.36) \mu \sim(2572.12,18.91)$ & $N \sim(\mu, 10.32) \mu \sim(277.22,7.55)$ \\
& 5 & $N \sim(\mu, 43.63) \mu \sim(6931.14,29.75)$ & $N \sim(\mu, 22.42) \mu \sim(1668.22,15.61)$ & $N \sim(\mu, 10.27) \mu \sim(273.73,7.51)$ \\
& 10 & $N \sim(\mu, 57.68) \mu \sim(12399.04,39.12)$ & $N \sim(\mu, 29.44) \mu \sim(3010.78,20.29)$ & $N \sim(\mu, 13.46) \mu \sim(525.32,9.64)$ \\
& 15 & $N \sim(\mu, 58.82) \mu \sim(12912.45,39.88)$ & $N \sim(\mu, 30.59) \mu \sim(3269.98,21.06)$ & $N \sim(\mu, 12.72) \mu \sim(460.09,9.15)$ \\
& 20 & $N \sim(\mu, 58.93) \mu \sim(12963.79,39.95)$ & $N \sim(\mu, 31.72) \mu \sim(3462.72,21.61)$ & $N \sim(\mu, 17.80) \mu \sim(998.23,12.53)$ \\
\hline
\end{tabular}

Step 3. Formulate a BCCLP model based on steps 1 and 2.

Step 4. Establish the operation optimization model for the gas-fired CCHP system based on BCCLP model.

Step 5. Convert birandom constraints into their respective deterministic equivalents based on equilibrium chance-constrained measure.

Step 6. Solve BCCLP model and generate the final solutions of objective values and decision variables under various conditions.

\section{Result Analysis and Discussion}

4.1. Result Analysis. The BCCLP model was developed for determining the optimal operation strategies of the gas-fired CCHP system to manage the energy (including electricity, heating, and cooling) flow reasonably and achieve the minimum cost. Therefore, this section is categorized into four groups: (i) cooling-supply system, (ii) heating-supply system, (iii) electricity-supply system, and (iv) system cost, respectively.

4.1.1. Cooling-Supply System. In order to minimize the operating and maintenance costs, the selection of operation strategies in the cooling-supply system (including absorption chillers and electrical chillers) is closely connected to operating efficiency and costs but also to the $\alpha$ value. Table 3 provides the operational strategies and resource consumption of the CCHP system under different $\alpha$ levels in the typical days of three seasons (i.e., winter, summer, and transition). As shown in Table 3, various $\alpha$ values will result in different operation strategies and schedule pattern. Firstly, the quantity of cooling sourced from both AC and EC 
decreases with the increase in $\alpha$ value. For example, when $\alpha$ increases from 0.01 to 0.1 , the cooling magnitude provided by $\mathrm{AC}$ at three seasons (i.e., winter, transition, and summer) was reduced, being from $8.53 \times 10^{3}, 63.13 \times 10^{3}$, and $235.84 \times 10^{3} \mathrm{MJ}$ to $8.43 \times 10^{3}, \quad 62.96 \times 10^{3}$, and $235.60 \times 10^{3} \mathrm{MJ}$, respectively; similarly, the quantity of cooling supplied by EC would decrease to $0.10 \times 10^{3}$, $2.01 \times 10^{3}$, and $38.83 \times 10^{3} \mathrm{MJ}$ from $0.13 \times 10^{3}, 2.06 \times 10^{3}$, and $38.93 \times 10^{3} \mathrm{MJ}$, respectively. This is due to the fact that the low $\alpha$ value corresponds to the high cooling requirement, leading to the high cooling output. Conversely, the high $\alpha$ value was associated with the low cooling demand, which was accompanied by the low cooling-generation amount.

In fact, other factors, including economic parameters and operational mechanism, also exert some influences on the operational strategies. Figure 3(a) shows the optimal operation strategy of the cooling-supply system during the typical days over three seasons. Figure 3(b) demonstrates the solutions of cooling-supply amounts of two facilities and their respective proportions during every month. According to Figure 3(a), the cooling demand is satisfied by the electric chiller at valley time (22:00-6:00); conversely, the absorption chiller is under full-load state during peak time $(8: 00-11: 00 ; 18: 00-22: 00)$ and flat time $(6: 00-8: 00 ; 11: 00-18: 00)$. This is because the change in the electricity price has an obvious influence on the operation strategies of the cooling-supply system, where the electricity price was divided into three levels. Such a change would lead to the various options of candidate equipment, where the electric chiller plays an important role at the valley time in order to realize the minimization of total system cost; correspondingly, the absorption chiller was used to provide the cooling output at other two periods. As shown in Figure 3(b), the cooling demand is covered mainly by the absorption chillers, where their annual average proportion will reach $97 \%$. The main reason is that, compared with electric chiller, the absorption chiller utilized recovered waste heat sourced from the gas turbine, which results in the low average operational cost and high energy-utilization efficiency.

4.1.2. Heating-Supply System. The heat-supply system includes the heat exchanger and auxiliary boiler, where the generation of optimal operation strategies mainly considers the following three aspects: the reduction of energy-supply cost, the improvement in energy-conversion efficiency, and energy provision safety, respectively. Similar to the coolsupply system pattern, the violation level is associated with energy demands and thus affects the operation strategies of heat-supply system. As shown in Table 3, the total quantity of heating power decreases with the increase in $\alpha$ value. For instance, when $\alpha$ grows from 0.01 to 0.1 , the total heat output has an obvious decrease during winter, transition, and summer, with the values changing from $257.45 \times 10^{3}$, $67.00 \times 10^{3}$, and $12.01 \times 10^{3} \mathrm{MJ}$ to $257.17 \times 10^{3}, 66.76 \times 10^{3}$, and $11.85 \times 10^{3} \mathrm{MJ}$, respectively. This is because, according to the BCCLP algorithm, the increase in $\alpha$ level is corresponding to the reduction of the heat demand, such that the provision amounts would decrease. Apart from $\alpha$ level, the operating strategies are also influenced by the operational costs of the equipment. As shown in Figure 4, the heat demand is met totally by the heat exchanger. This is partly because the CCHP system executes the FTL strategy, which means that the heat exchanger will be adequate to cover all heat requirements, and there is no need to provide additional heat by the auxiliary boiler. Another reason is that the heat exchanger absorbed the recovered waste heat provided by the gas turbine, with a low cost compared to the auxiliary boiler.

4.1.3. Electricity-Supply System. In the electric supply system, the electricity requirements are satisfied by both the gas turbine and purchased electricity from the grid, respectively. The electricity amounts provided by the above two means are reflected in Table 3 and Figure 5. As discussed in the previous section, the determination of $\alpha$ level also would affect electricity-provision strategy through changing the electricity demands. For example, as described in Table 3, the electric quantity supplied by the gas turbine and purchased from the grid over three seasons decreases with the increase in $\alpha$ level. Specifically, when $\alpha$ grows from 0.01 to 0.1 , the electricity sourced from the gas turbine would be reduced from $23.11 \times 10^{3}, 10.95 \times 10^{3}$, and $20.23 \times 10^{3} \mathrm{~kW}$ to $23.07 \times 10^{3}, 10.91 \times 10^{3}$, and $20.12 \times 10^{3} \mathrm{~kW}$ in the winter, transition, and summer, respectively, while purchased electricity from grid would drop to $12.95 \times 10^{3}, 33.01 \times 10^{3}$, and $41.69 \times 10^{3} \mathrm{~kW}$ from $13.11 \times 10^{3}, 33.20 \times 10^{3}$, and $41.93 \times 10^{3} \mathrm{~kW}$, respectively. Similarly, the operating strategy of this system also exhibited seasonal variation. Figure 5(a) demonstrated the electricity magnitude at a whole year. As shown in Figure 5(a), the electric demand from December to February is mainly satisfied by the gas turbine whose output would reach $32.59 \times 10^{3}, 23.07 \times 10^{3}$, and $37.22 \times 10^{3} \mathrm{~kW}$, respectively. Conversely, the electric demand from June to September is mainly provided by the purchased electricity, which was $44.96 \times 10^{3}, 41.69 \times 10^{3}, 41.66 \times 10^{3}$, and $45.16 \times 10^{3} \mathrm{~kW}$, respectively. The reason is that total electricity amounts generated from the gas turbine are the sum of the electricity supplied to the users and the electricity used to drive the electric chiller. In summer, the consumed electricity of electric chiller would increase with the increase in the cooling demand, which would lead to the reduction in generated electricity supplied to the users, leading to more purchased electricity. On the contrary, the electricity provided to the users would increase significantly when cooling demand becomes decreased in the winter. Meanwhile, the high heating demand needs more recovered heat to drive the heat exchanger in winter, which would result in an increase in the natural gas consumption, as shown in Figure 5(a).

Figure 5(b) described the average hourly electricityprovision quantity during the typical days over three seasons. As shown in Figure 5(b), in summer, the peak output of the gas turbine would be from 12:00 to 14:00 with the values of $1.62 \times 10^{3}, 1.64 \times 10^{3}$, and $1.96 \times 10^{3} \mathrm{~kW}$, respectively. As 
TABLE 3: CCHP's operation strategies under different $\alpha$ levers in typical day during winter, transition, and summer.

\begin{tabular}{|c|c|c|c|c|c|c|c|c|c|}
\hline \multirow{2}{*}{ Item } & \multicolumn{3}{|c|}{$\alpha=0.1$} & \multicolumn{3}{|c|}{$\alpha=0.05$} & \multicolumn{3}{|c|}{$\alpha=0.01$} \\
\hline & Winter & Transition & Summer & Winter & Transition & Summer & Winter & Transition & Summer \\
\hline $\begin{array}{l}\text { Gas consumption } \\
\left(\mathrm{m}^{3}\right)\end{array}$ & 16396.70 & 7756.32 & 14299.12 & 16406.02 & 7764.95 & 14307.37 & 16423.51 & 7781.13 & 14321.83 \\
\hline $\begin{array}{l}\text { Supplied cooling by } \\
\mathrm{AC}(\mathrm{MJ})\end{array}$ & 8425.95 & 62954.16 & 235598.58 & 8463.78 & 63013.72 & 235681.14 & 8534.62 & 63125.49 & 235836.02 \\
\hline $\begin{array}{l}\text { Supplied cooling by } \\
\text { EC (MJ) }\end{array}$ & 103.56 & 2012.99 & 38833.40 & 113.96 & 2029.74 & 38865.52 & 133.46 & 2061.18 & 38925.79 \\
\hline $\begin{array}{l}\text { Supplied heating by } \\
\text { HE (MJ) }\end{array}$ & 257116.17 & 66759.25 & 11847.16 & 257231.65 & 66843.22 & 11903.64 & 257448.28 & 67000.72 & 12009.58 \\
\hline $\begin{array}{l}\text { Supplied electricity } \\
\text { by GT }(\mathrm{kW})\end{array}$ & 23070.16 & 10913.14 & 20118.87 & 23083.27 & 10925.28 & 20130.48 & 23107.88 & 10948.05 & 20226.90 \\
\hline $\begin{array}{l}\text { Purchased } \\
\text { electricity }(\mathrm{kW})\end{array}$ & 12942.46 & 33006.19 & 41686.72 & 13004.89 & 33074.27 & 41762.36 & 13122.00 & 33201.97 & 41929.58 \\
\hline System cost (RMB) & 1471820.00 & 1234922.00 & 1832058.00 & 1473759.00 & 1236843.00 & 1834206.00 & 1477396.00 & 1240445.00 & 1866149.00 \\
\hline
\end{tabular}

Note. AC denotes absorption chillers; EC denotes electrical chillers; HE denotes heat exchanger; GT denotes gas turbine.

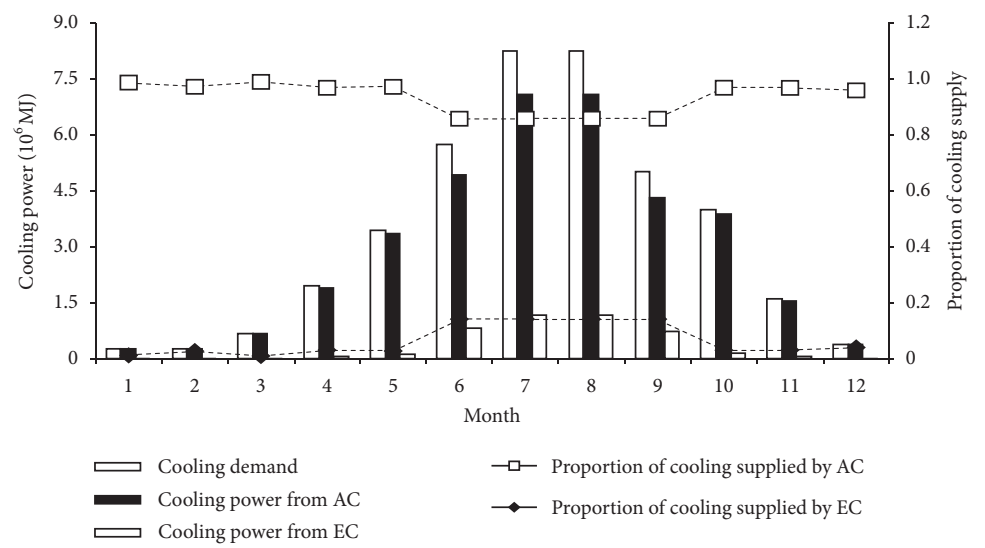

(a)

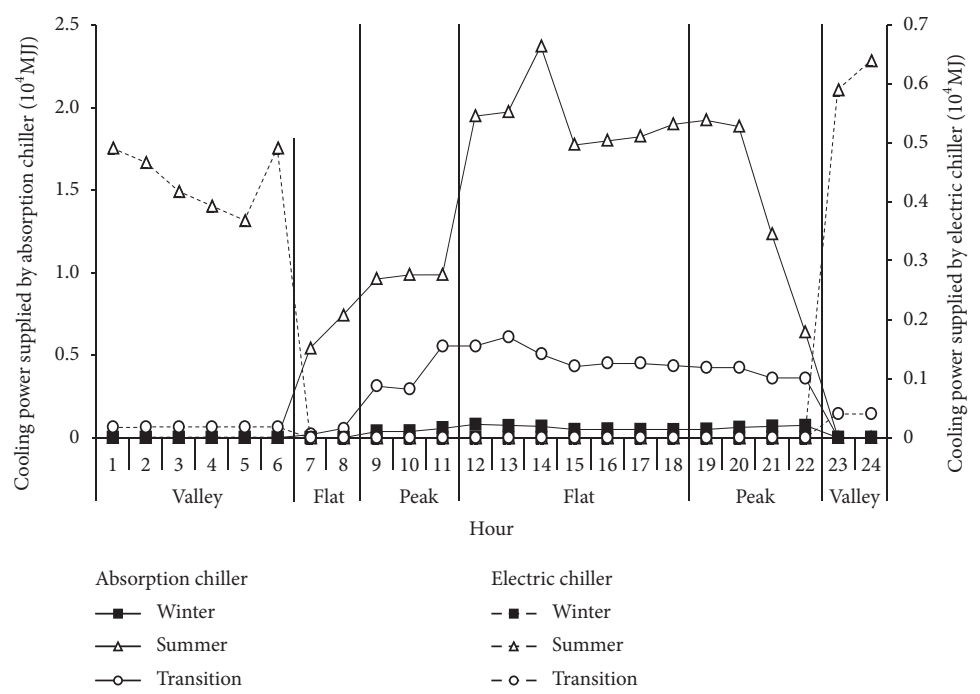

(b)

FIGURE 3: Operation strategies of cooling-supply system: (a) annual operation strategy; (b) typical daily operation strategy over three seasons. 


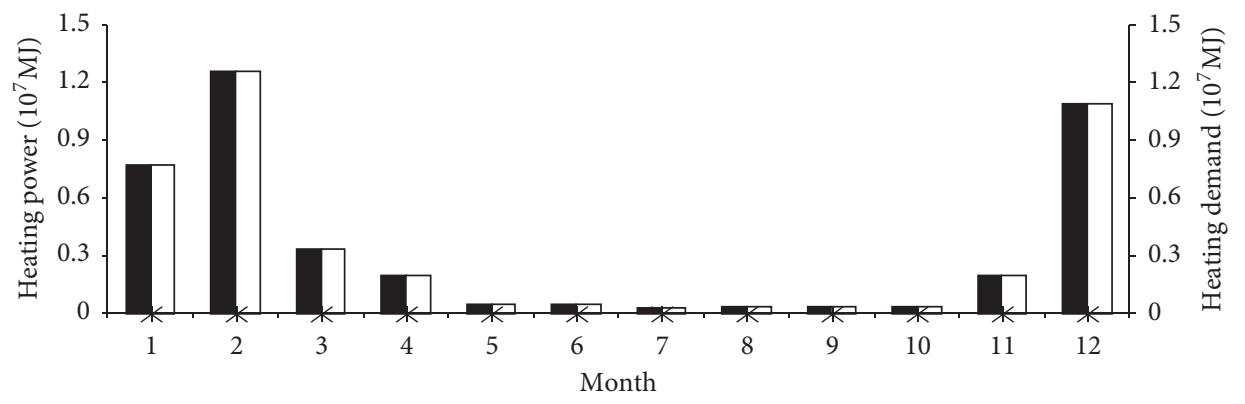

Heating demand

Heating power from $\mathrm{HE}$

* Heating power from $\mathrm{AB}$

(a)

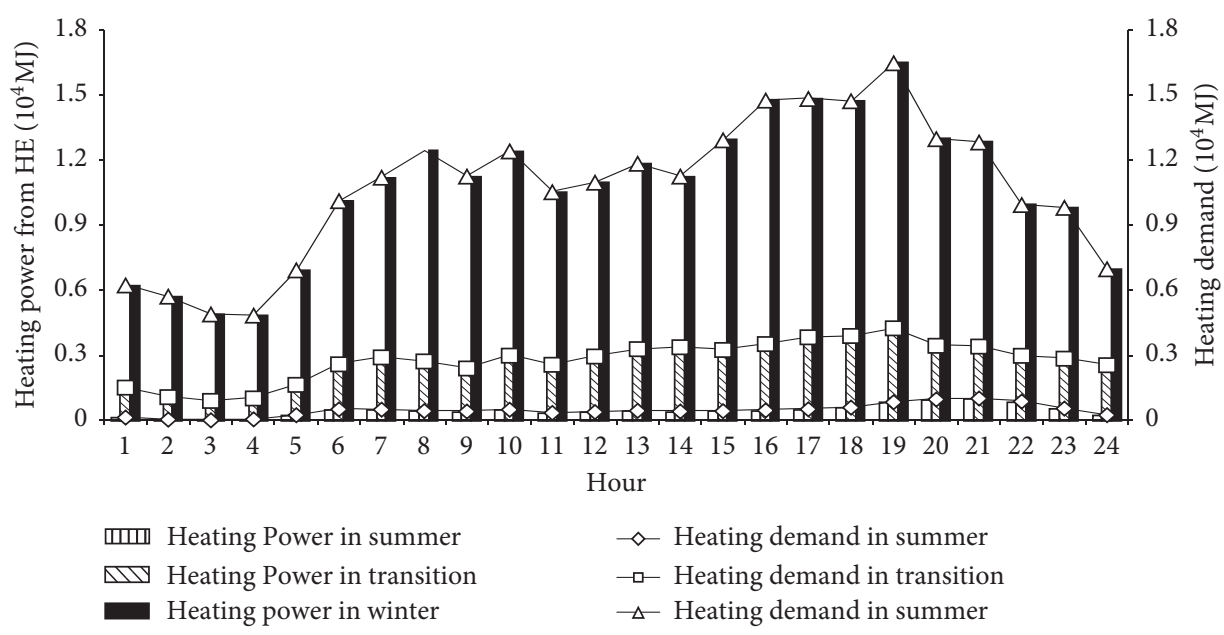

(b)

FIGURE 4: Operation strategies of heating-supply system: (a) annual operation strategy; (b) typical daily operation strategy over three seasons.

for other time periods, the output power of the gas turbine would be extremely low. Particularly at 3:00, it would be only $4.43 \mathrm{~kW}$. In winter, the output of the gas turbine would be very large during the period of 16:00-19:00 and the peak hour would be at 19:00 with maximum output $1.68 \times 10^{3} \mathrm{~kW}$. The minimum output would be $0.42 \times 10^{3} \mathrm{~kW}$ at $4: 00$. Such a change is mainly because the power curve of the gas turbine is consistent with the energy-demand curve. In detail, the recovered heat used for the heat exchanger would increase as the increase in heating demand level at winter, which means that the gas turbine would produce the electricity more compared to other periods.

4.1.4. System Cost. This section describes the objective value of the proposed model. As demonstrated in Table 3, there is a strong negative correlation between $\alpha$ level and total system cost. For example, when $\alpha$ grows from 0.01 to 0.1 , the operating cost would be downward from $1.87 \times 10^{6}, 1.48 \times 10^{6}$, and $1.24 \times 10^{6} \mathrm{RMB}$ to $1.83 \times 10^{6}, 1.47 \times 10^{6}$, and $1.23 \times 10^{6}$ $\mathrm{RMB}$, respectively; correspondingly, the natural gas consumption would decrease to $16.40 \times 10^{3}, 7.76 \times 10^{3}$, and $14.30 \mathrm{~m}^{3}$ from $16.42 \times 10^{3}, 7.78 \times 10^{3}$, and $14.32 \mathrm{~m}^{3}$, respectively. This was due to the fact that low $\alpha$ level (i.e., high electricity and energy demand) corresponds to increased reliability in meeting the requirements, which led to the increases of system cost and natural gas consumption; conversely, high $\alpha$ level was related to a decreased security in satisfying the demands, thus resulting in the reductions of system cost and natural gas consumption. The above results disclose that there existed a tradeoff between the system cost and system-failure risk. There is a common problem associated with CCHP system that the energy supply may be insufficient to meet the peak demand; it thus recommends a more conservative solution with the high system cost as the operational strategy.

4.2. Discussion. From the above analysis, some factors, including the energy demand, electrical price, and natural gas price, exert the influence on the generated results of BCCLP model. Therefore, it is essential to perform the sensitivity analysis for evaluating the effect of those factors on the economy of the CCHP system in this section, where the energy demand, electrical price, and natural gas price are designed at the variation ranges $+20 \%$ to $+100 \%,-20 \%$ to $+20 \%$, and $-20 \%$ to $+20 \%$, respectively. Table 4 reflects the influences of electrical price, natural gas price, and energy 


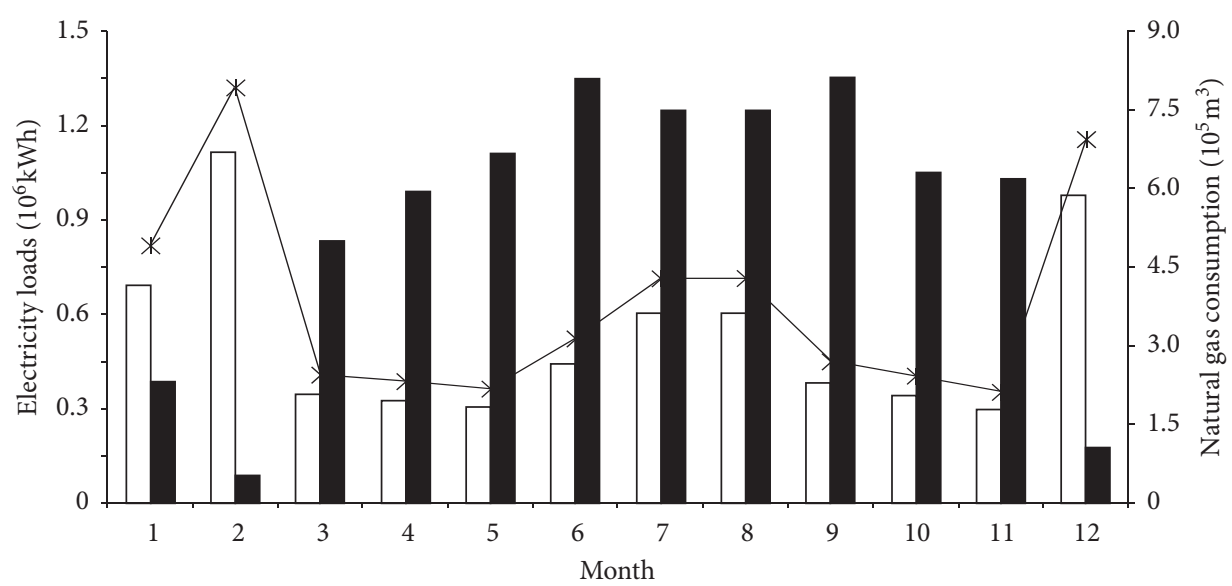

Electricity from gas turbine

- Purchased electricity

* Natural gas consumption

(a)
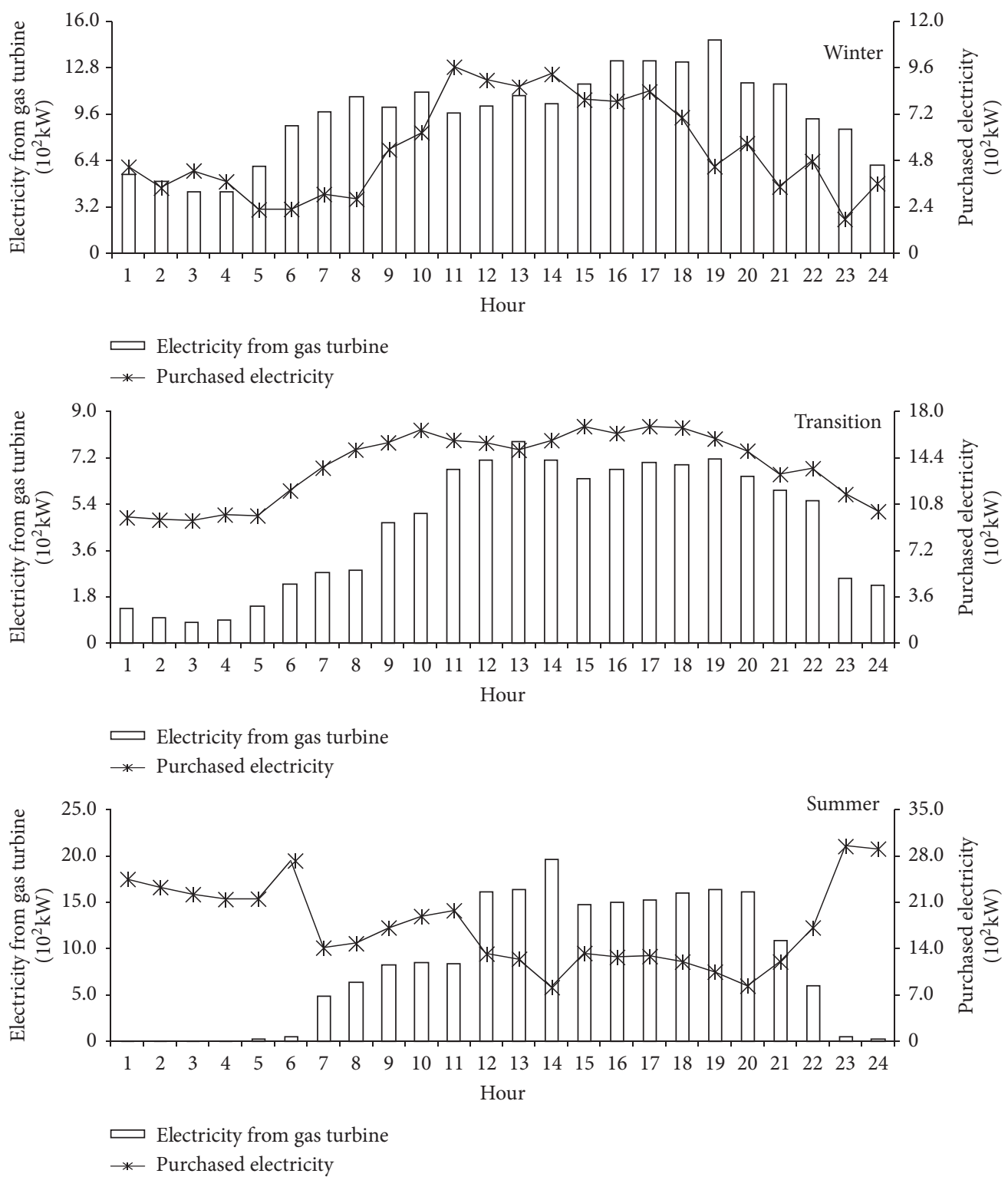

(b)

FIGURE 5: Operation strategies of electricity-supply system: (a) annual operation strategy; (b) typical daily operation strategy over three seasons. 
TABLE 4: System cost variation based on change of sensitivity parameters.

\begin{tabular}{|c|c|c|c|c|c|c|c|}
\hline \multirow[b]{2}{*}{ Item } & \multirow[b]{2}{*}{ Parameter variation (\%) } & \multicolumn{2}{|c|}{ Winter } & \multicolumn{2}{|c|}{ Transition } & \multicolumn{2}{|c|}{ Summer } \\
\hline & & Cost (RMB) & Change rate (\%) & Cost (RMB) & Change rate $(\%)$ & Cost (RMB) & $\begin{array}{l}\text { Change } \\
\text { rate }(\%)\end{array}$ \\
\hline \multirow{4}{*}{ Electricity price } & -20 & 1414768 & -3.88 & 1096544 & -11.21 & 1672504 & -8.71 \\
\hline & -10 & 1443294 & -1.94 & 1165733 & -5.60 & 1752281 & -4.35 \\
\hline & +10 & 1500346 & 1.94 & 1304112 & 5.60 & 1911834 & 4.35 \\
\hline & +20 & 1528872 & 3.88 & 1373301 & 11.21 & 1991610 & 8.71 \\
\hline \multirow{4}{*}{ Natural gas price } & -20 & 1235970 & -16.02 & 1126954 & -8.74 & 1626379 & -11.23 \\
\hline & -10 & 1353895 & -8.01 & 1180938 & -4.37 & 1729218 & -5.61 \\
\hline & +10 & 1589745 & 8.01 & 1288906 & 4.37 & 1934897 & 5.61 \\
\hline & +20 & 1707670 & 16.02 & 1342890 & 8.74 & 2037736 & 11.23 \\
\hline \multirow{3}{*}{ Heating demand } & +25 & 1635522 & 11.12 & 1276131 & 3.34 & 1838961 & 0.38 \\
\hline & +50 & 1824295 & 23.95 & 1317339 & 6.67 & 1845865 & 0.75 \\
\hline & +100 & 2312825 & 57.14 & 1399756 & 13.35 & 1859673 & 6.03 \\
\hline \multirow{3}{*}{ Cooling demand } & +25 & 1476254 & 0.30 & 1267951 & 2.67 & 1968859 & 7.47 \\
\hline & +50 & 1480688 & 0.60 & 1300980 & 5.35 & 2108684 & 15.10 \\
\hline & +100 & 1489555 & 1.20 & 1367038 & 10.70 & 2438152 & 33.08 \\
\hline \multirow{3}{*}{ Electricity demand } & +25 & 1672031 & 13.61 & 1469416 & 18.99 & 2146366 & 17.16 \\
\hline & +50 & 1872241 & 27.21 & 1703909 & 37.98 & 2460675 & 34.31 \\
\hline & +100 & 2272663 & 54.41 & 2279530 & 84.59 & 3089293 & 68.62 \\
\hline
\end{tabular}

demands on the system cost. Firstly, the total system cost is more sensitive to the change in electrical price in transition than that in summer and winter. For instance, as the electrical price increases from $-20 \%$ to $20 \%$, the fluctuations in system' cost in summer and winter are basically the same with no obvious increases, that is, only increase from -8.71 to $8.71 \%$ and from $-3.88 \%$ to $3.88 \%$, while a dramatic increase in the system cost from $-11.23 \%$ to $11.23 \%$ could be observed in the transition period. The reason is that purchased electricity amounts in the transition are the highest among a year. Secondly, compared with the transition season, the natural gas price has a greater influence on the system cost in winter and summer. For example, the cost has a distinct variation in summer with an increase of $11.25 \%$ when the natural gas price increases by $20 \%$ and even rises up to $16.02 \%$ in winter. But in transition, a $20 \%$ increase of the natural gas price only causes a slight change of the system's cost by up to $8.74 \%$. This is because the heating and cooling loads in winter and summer are much larger than those in transition, and thus there is more natural gas that needs to be purchased.

The energy demand is another key factor that influences the system cost. As shown in Table 4, the heating demand has a high sensitivity to the variation of the cost in winter and has a slight effect on the cost in summer. For example, the variation in the heating demand is assumed to be $100 \%$, which would result in a $57.14 \%$ increase in the total cost in winter, but only an increase of $6.30 \%$ in summer. Compared with the heating demand, the cooling demand has the opposite sensitivity in the above seasons. For example, a $100 \%$ variation in cooling demand would lead to a $33.08 \%$ increase in the total cost in summer. The difference in energy demand among various seasons could explain this phenomenon. In winter, the heating demand is much larger than cooling demand, so it is the key factor. On the contrary, the cooling demand is very large in summer while the heating demand is relatively low, and thus the cost would be sensitive to cooling demand. In transition, both heating and cooling demand would have a significant influence on the cost. In addition, electric demand would also have an important effect on the economy. For instance, a $100 \%$ increase in the electricity demand causes a change in the system's cost by up to $84.59 \%, 68.28 \%$, and $57.41 \%$ at three seasons, respectively.

The sensitivity analysis result has revealed the influence rules of the above sensitive factors on the system economy, which could be classified into three categories: (i) in winter, the increase in natural gas price, heating, and electric demands would result in the large variation in total system costs; (ii) in summer, the cooling demand, electric demand, and the electrical price are key factors that affect the system economy; (iii) in transition, the system cost has moderate sensitivity to fluctuations of all parameters. It is beneficial to decision-makers for generating rational and reliable operational pattern through paying more attention to improve the accuracy of the key factors in the site survey and experts' consultation.

Moreover, the BCCLP model still needs to be improved, especially in the following three aspects. Firstly, the BCCLP model based on birandom chance-constrained linear programming is proposed for identifying the uncertainties associated with the CCHP system and generating a variety of cost-effective operation strategies reflecting the tradeoff between system economy and reliability; however, the energy generation, conversion, transition, and utilization processes in BCCLP model are formulated by some simplified mathematical equations. For example, there are only three equations to express the conversion of natural gas to electricity and heating quantity in this research. This simplified way is beneficial to formulate and solve the CCHP system operation optimization model but has difficulties in generating accurate and reliable solutions. This is because it is a complicated process in the actual production, which is related to a variety of operational conditions, including flue-gas temperature and turbine pressure. Therefore, it is necessary to enhance the 
accuracy and applicability of optimization model through incorporating the output of the mechanism model or simulation software (i.e., Epsilon and Aspen) into the optimization model. Secondly, only the birandom variables are used to describe the energy demands of the CCHP system; in fact, some intrinsic and human-induced uncertainties might exist in the CCHP system. For instance, the electrical and natural price is influenced by the resources' availability and policy regulations and should be described as the interval values. Performance of the system equipment exhibits the uncertain characteristics caused by their service time and the subjective judgments of humans, which could be expressed as a fuzzy parameter. Hence, other uncertain optimization techniques, such as fuzzy and interval optimization methods, should be incorporated into the model in order to handle multiple uncertainties involved in the CCHP system. Thirdly, the minimization in the system cost is considered in the BCCLP model. In fact, the minimization in the system cost is considered as the objective function in the BCCLP model. In fact, the minimization of pollutant-emission amounts and the maximization of primary energy rate are also major concerns for the managers of CCHP system, in addition to the economic objective. To obtain a balance among various objectives in real-world decision makings, the multiobjective programming (MOP) technique is desired. Previously, MOP has been integrated with some optimization models and successfully applied in many CCHP system management problems $[4,10]$. It has a strong potential to be incorporated with the proposed BCCLP model for handling more complicated cases in the future. Finally, the objective function in this study is assumed to be linear form; in fact, the relationship between maintenance cost and load rate may be nonlinear, rather than the linear form. This will lead to a nonlinear objective function. Because the focus of this research is to develop the BCCLP model for supporting the operation optimization of CCHP system, it is thus desired to examine the possibility of an integrated model of BCCLP and nonlinear programming in the future.

\section{Conclusion}

In this study, a BCCLP model was developed for determining the optimal operation strategies of the gas-fired CCHP system for a five-star hotel in Shanghai Pudong New Area, China. Because the system parameters, including electric demand, cooling demand, and heating demand, exhibit obvious dual-random characteristics in the parameters-identification process, such that the birandom variable was innovatively incorporated into the optimization model for describing their fluctuated characteristics them. A variety of optimal operation strategies for the gasfired CCHP system were obtained through adjusting predetermined constraint-violation levels, which indicated that the BCCLP model was useful in helping local managers gain in-depth insights into the CCHP system, avoid the deviation caused by the oversimplified uncertain expression, and analyze the tradeoffs between system economy and reliability, as well as establishing the costeffective operation strategies. Several findings could be summarized as follows:

(i) For the cooling-supply system, the cooling demand was satisfied mainly by the absorption chiller for one year. Meanwhile, due to the effect of step tariff on operational cost of electrical chiller, the cooling demand was provided totally by the electric chillers at valley time, and absorption chillers kept full-load operations during the rest periods. (ii) In terms of the heating-supply system, the heating demand was met totally by the heat exchanger due to its low running costs and high energy-utilization efficiency. (iii) For the electric supply system, the operating strategy exhibited the seasonal variation. The electric demand in winter was mainly by aid of the gas turbine; conversely, it was satisfied through buying electricity in summer. (iv) The sensitivity analysis reflected that five factors have the influences on system economy over three seasons, which suggested that comprehensive investigation and consultation are finished for improving the system performance. In the future, high-precision mechanism models or simulation software, multiobjective programming methods, and two types of uncertain optimization techniques should be incorporated into proposed model for tackling more complex issues.

\section{Data Availability}

The data used to support the findings of this study are included within the article.

\section{Conflicts of Interest}

The authors declare no conflicts of interest.

\section{Authors' Contributions}

Ye Xu, Zhe Bao, and Jiheng Li conceived and designed the research. Wei Li, Zhaoyi Huo, Hansheng Yang, and Zhe Bao collected the data. Zhaoyi Huo contributed to supervision. Ye Xu, Zhe Bao, Wei Li, and Hansheng Yang formulated the optimization model. Zhe Bao, Ye Xu, Jiheng Li, and Mengran Li performed the data analyses and manuscript preparation. Zhe Bao, Ye Xu, Wei Li, and Hansheng Yang wrote the paper. Wei $\mathrm{Li}, \mathrm{Ye} \mathrm{Xu}$, and Jiheng $\mathrm{Li}$ gave the comments and helped to revise the paper.

\section{Acknowledgments}

The authors are very grateful to the Open Fund of Beijing Key Laboratory of Demand Side Multi-Energy Carriers Optimization and Interaction Technique (YDB 512001901516) for supporting this research. 


\section{References}

[1] Y. Liu, Y. Qian, H. Xiao, and S. Yang, "Techno-economic and environmental analysis of coal-based synthetic natural gas process in China," Journal of Cleaner Production, vol. 166, pp. 417-424, 2017.

[2] X. Xie, H. Ai, and Z. Deng, "Impacts of the scattered coal consumption on PM2.5 pollution in China," Journal of Cleaner Production, vol. 245, 2019.

[3] B. P. Global, BP Statistical Review of World Energy June 2017, 2017.

[4] Z.-F. Tan, H.-J. Zhang, Q.-S. Shi, Y.-H. Song, and L.-W. Ju, "Multi-objective operation optimization and evaluation of large-scale NG distributed energy system driven by gas-steam combined cycle in China," Energy and Buildings, vol. 76, pp. 572-587, 2014.

[5] G. Chicco and P. Mancarella, "Distributed multi-generation: a comprehensive view," Renewable and Sustainable Energy Reviews, vol. 13, no. 3, pp. 535-551, 2009.

[6] R. Viral and D. K. Khatod, "Optimal planning of distributed generation systems in distribution system: a review," Renewable and Sustainable Energy Reviews, vol. 16, no. 7, pp. 5146-5165, 2012.

[7] B. Yan, S. Xue, Y. Li, J. Duan, and M. Zeng, "Gas-fired combined cooling, heating and power (CCHP) in Beijing: a techno-economic analysis," Renewable and Sustainable Energy Reviews, vol. 63, pp. 118-131, 2016.

[8] P. J. Mago, N. Fumo, and L. M. Chamra, "Performance analysis of CCHP and CHP systems operating following the thermal and electric load," International Journal of Energy Research, vol. 33, no. 9, pp. 852-864, 2009.

[9] P. J. Mago and L. M. Chamra, "Analysis and optimization of CCHP systems based on energy, economical, and environmental considerations," Energy and Buildings, vol. 41, no. 10, pp. 1099-1106, 2009.

[10] P. J. Mago and A. K. Hueffed, "Evaluation of a turbine driven CCHP system for large office buildings under different operating strategies," Energy and Buildings, vol. 42, no. 10, pp. 1628-1636, 2010.

[11] Z. Wang, W. Han, N. Zhang, B. Su, M. Liu, and H. Jin, "Analysis of inlet air throttling operation method for gas turbine in performance of CCHP system under different operation strategies," Energy Conversion and Management, vol. 171, pp. 298-306, 2018.

[12] G. Abdollahi and H. Sayyaadi, "Application of the multiobjective optimization and risk analysis for the sizing of a residential small-scale CCHP system," Energy and Buildings, vol. 60, pp. 330-344, 2013.

[13] Z. Li, Q. An, J. Zhao, S. Deng, L. Kang, and Y. Wang, “Analysis of system optimization for CCHP system with different feedin tariff policies," Energy Procedia, vol. 105, pp. 2484-2491, 2017.

[14] F. Li, B. Sun, C. Zhang, and L. Zhang, "Operation optimization for combined cooling, heating, and power system with condensation heat recovery," Applied Energy, vol. 230, pp. 305-316, 2018.

[15] S. Lu, Y. Li, and H. Xia, "Study on the configuration and operation optimization of CCHP coupling multiple energy system," Energy Conversion and Management, vol. 177, pp. 773-791, 2018.

[16] C. Qin, J. Tang, and Y. Zhang, "An efficient algorithm for CCHP system sizing and an operational optimization model based on LP," Journal of Natural Gas Science and Engineering, vol. 25, pp. 189-196, 2015.
[17] B. Su, W. Han, Y. Chen, Z. Wang, W. Qu, and H. Jin, "Performance optimization of a solar assisted CCHP based on biogas reforming," Energy Conversion and Management, vol. 171, pp. 604-617, 2018.

[18] X. Wang, C. Yang, M. Huang, and X. Ma, "Multi-objective optimization of a gas turbine-based CCHP combined with solar and compressed air energy storage system," Energy Conversion and Management, vol. 164, pp. 93-101, 2018.

[19] G. Yang and X. Zhai, "Optimization and performance analysis of solar hybrid CCHP systems under different operation strategies," Applied Thermal Engineering, vol. 133, pp. 327340, 2018.

[20] X. Zhu, X. Zhan, H. Liang et al., "The optimal design and operation strategy of renewable energy-CCHP coupled system applied in five building objects," Renewable Energy, vol. 146, pp. 2700-2715, 2020.

[21] I. Ersoz and U. Colak, "Combined cooling, heat and power planning under uncertainty," Energy, vol. 109, pp. 1016-1025, 2016.

[22] I. Ersoz and U. Colak, "A stochastic evaluation of investments in combined cooling, heat, and power systems," Applied Thermal Engineering, vol. 146, pp. 376-385, 2019.

[23] C. He, Q. Zhang, J. Ren, and Z. Li, "Combined cooling heating and power systems: sustainability assessment under uncertainties," Energy, vol. 139, pp. 755-766, 2017.

[24] L. Ji, D. X. Niu, and G. H. Huang, "An inexact two-stage stochastic robust programming for residential micro-grid management-based on random demand," Energy, vol. 67, pp. 186-199, 2014.

[25] C. Marino, M. Marufuzzaman, M. Hu, and M. D. Sarder, "Developing a CCHP- microgrid operation decision model under uncertainty," Computers \& Industrial Engineering, vol. 115, pp. 354-367, 2018.

[26] X. Shen, Q. Guo, and H. Sun, "Regional integrated energy system planning considering energy price uncertainties: a two-stage stochastic programming approach," Energy Procedia, vol. 158, pp. 6564-6569, 2019.

[27] C. Zhang, X. Xue, Q. Du, Y. Luo, and W. Gang, "Study on the performance of distributed energy systems based on historical loads considering parameter uncertainties for decision making," Energy, vol. 176, pp. 778-791, 2019.

[28] C. Y. Zhou, G. H. Huang, J. P. Chen, and X. Y. Zhang, "Inexact fuzzy chance-constrained fractional programming for sustainable management of electric power systems," Mathematical Problems in Engineering, vol. 2018, Article ID 5749016, 13 pages, 2018.

[29] C. Y. Zhou, G. H. Huang, and J. P. Chen, "Planning of electric power systems considering virtual power plants with dispatchable loads included: an inexact two-stage stochastic linear programming model," Mathematical Problems in Engineering, vol. 2018, Article ID 7049329, 12 pages, 2018.

[30] L. Ji, D. X. Niu, G. H. Huang, W. Li, and Z. P. Liu, "Environmental and economic optimization model for electric system planning in ningxia, China: inexact stochastic riskaversion programming approach," Mathematical Problems in Engineering, vol. 2015, Article ID 236958, 17 pages, 2015.

[31] D. F. Teshomei, P. F. Correia, and K. L. Lian, "Stochastic optimization for network-constrained power system scheduling problem," Mathematical Problems in Engineering, vol. 2015, Article ID 694619, 17 pages, 2015.

[32] J. Peng and B. Liu, "Birandom variables and birandom programming," Computers \& Industrial Engineering, vol. 53, no. 3, pp. 433-453, 2007. 
[33] J. Xu and C. Ding, "A class of chance constrained multiobjective linear programming with birandom coefficients and its application to vendors selection," International Journal of Production Economics, vol. 131, no. 2, pp. 709-720, 2011.

[34] J. $\mathrm{Xu}$ and $\mathrm{Z}$. Tao, "A class of multi-objective equilibrium chance maximization model with twofold random phenomenon and its application to hydropower station operation," Mathematics and Computers in Simulation, vol. 85, pp. 11-33, 2012.

[35] J. Xu and X. Zhou, "A class of multi-objective expected value decision-making model with birandom coefficients and its application to flow shop scheduling problem," Information Sciences, vol. 179, no. 17, pp. 2997-3017, 2009.

[36] M. Liu, Y. Shi, and F. Fang, "Combined cooling, heating and power systems: a survey," Renewable and Sustainable Energy Reviews, vol. 35, pp. 1-22, 2014.

[37] Y. Xu, G. H. Huang, X. S. Qin, and M. F. Cao, "SRCCP: a stochastic robust chance-constrained programming model for municipal solid waste management under uncertainty," Resources, Conservation and Recycling, vol. 53, no. 6, pp. 352363, 2009.

[38] L. Wang, G. Huang, X. Wang, and H. Zhu, "Risk-based electric power system planning for climate change mitigation through multi-stage joint-probabilistic left-hand-side chanceconstrained fractional programming: a Canadian case study," Renewable and Sustainable Energy Reviews, vol. 82, pp. 1056-1067, 2018. 